\title{
BcS: Jogos Digitais no Auxílio do Desenvolvimento de Crianças Especiais com Atraso na Linguagem
}

\author{
Diogo Luiz Ceccon ${ }^{1}$, Josiane Brietzke Porto ${ }^{1}$ \\ ${ }^{1}$ Escola Politécnica - Universidade do Vale dos Sinos (UNISINOS) \\ Av. Unisinos, 950 - 93.022-750 - São Leopoldo - RS - Brasil \\ diogo_lzc@hotmail.com, josibrietzke@unisinos.br
}

\begin{abstract}
In view of the history and potential of games in the educational context, a portable interactive digital game was developed, under the Design Science Research method, aimed at special children with language development delay, aiming to stimulate speech. In the first evaluation cycle, children with Down Syndrome from a school in Curitiba / PR were offered a new experience of learning and speech stimulation, consisting of five types of varied activities, with the emission of sounds that can be repeated by the user. Such digital resources were well accepted by both the professional and the children involved, who showed evolution and interest during speech stimulation activities.
\end{abstract}

Resumo. Diante da história e potencial dos jogos no contexto educacional foi desenvolvido um jogo digital interativo portátil, sob método Design Science Research, BcS, voltado às crianças especiais com atraso no desenvolvimento da linguagem, visando estimular a fala. Em primeiro ciclo de avaliação se ofereceu às crianças com Síndrome de Down de uma escola em Curitiba/PR, uma nova experiência de aprendizado e de estimulação de fala, constituída de cinco tipos de atividades variadas, com emissão de sons que podem ser repetidos pelo usuário. Tais recursos digitais tiveram boa aceitação tanto pela profissional e quanto pelas crianças envolvidas, que demonstraram evolução $e$ interesse durante as atividades de estimulação da fala.

\section{Introdução}

Crianças com necessidades especiais necessitam de um acompanhamento próximo, tanto por parte dos pais quanto dos professores. Nesse aspecto, o apoio de profissionais especializados pode ajudar no seu desenvolvimento. Para Prates e Martins (2013), muitos dos problemas de comunicação ocorridos durante a infância podem ser minimizados e até evitados por meio da estimulação, orientação aos familiares e identificação precoce. Dificuldades no atraso do desenvolvimento da linguagem em geral (escrita, fala, leitura etc.) é uma área que pode ser trabalhada e melhorada nas instituições educacionais as quais essas crianças frequentam.

Com o crescimento do uso da tecnologia e maior acessibilidade das pessoas a estas ferramentas atualmente, faz-se necessário a utilização de meios digitais, como uma medida para combater as dificuldades apresentadas. Além do poder de aprendizado que os jogos educativos oferecem, eles trazem às crianças uma forma lúdica de aprender, principalmente, para as que possuem necessidades especiais.

Jogos educativos são encontrados em diversos locais na web ou em lojas de aplicativos, no caso de smartphones e tablets. Porém, é difícil encontrar jogos que possam ser utilizados com crianças portadoras de necessidades especiais, uma vez que 
IX Congresso Brasileiro de Informática na Educação (CBIE 2020)

Anais do XXXI Simpósio Brasileiro de Informática na Educação (SBIE 2020)

estes jogos possuem um grau elevado de complexidade levando a falta de interesse na sua utilização, haja vista não terem sidos projetados para esse fim.

Ademais, mesmo com o auxílio de profissionais e de estimulação, crianças com necessidades especiais necessitam de tempo prolongado para comunicar-se com articulação adequada de palavras e com um bom vocabulário. Sendo assim, é possível utilizar jogos digitais para auxiliar o desenvolvimento da linguagem de crianças especiais? Nesse sentido, esse artigo teve por objetivo o desenvolvimento de jogos digitais educativos, que auxiliem no desenvolvimento da linguagem de crianças especiais, na faixa etária entre 3 e 5 anos, utilizando o framework Construct 2. Dessa forma oferece-se ao profissional da área da educação uma ferramenta tecnológica para auxiliar em atividades de desenvolvimento dessas crianças de forma lúdica e prática.

Sob o método Design Science Research foram identificadas abordagens teóricas e técnicas de aprendizagem com jogos digitais para crianças especiais. Protótipos de jogos digitais foram criados e aprimorados para a estimulação da fala dessas crianças, além de avaliados quanto à utilidade e efetividade no desenvolvimento da linguagem de crianças com Síndrome de Down (SD) em contexto real, por meio de estudo de caso.

Crianças especiais com SD têm perfil de aprendizagem diferenciado, forte consciência visual e habilidades de aprender visualmente, com facilidade em atividades práticas e de apoio visuais. Entretanto, estudos anteriores apontam existência de déficit no desenvolvimento linguístico dessas crianças, se comparadas às que não possuem deficiência (Lima, Delgado e Cavalcante, 2016). Crianças com SD de menor idade preferem usar gestos ao se comunicar, possuem maiores dificuldades ao desenvolver a linguagem falada e um desenvolvimento variado e mais lento (Rangel e Ribas, 2011).

Assim, recursos digitais e discussão acerca do desenvolvimento da linguagem em crianças com SD são necessários, em virtude de ser relativamente conhecido e comum nas relações diárias, em processos educacionais inclusivos. Os resultados deste trabalho podem aprimorar o processo de desenvolvimento da linguagem, por meio jogos digitais, aproveitando-se da facilidade do acesso à tecnologia, tornando-o atrativo para a criança e como uma ferramenta para o profissional especializado.

\section{Fundamentação Teórica}

\subsection{Síndrome de Down}

Síndrome de Down (SD) foi registrada pelo médico britânico, John Langdon Haydon Down, em 1866, causada pela trissomia do cromossomo 21, a qual foi comprovada somente em 1959, pelas equipes do Dr. Jerome Lejeune e da Dra. Patrícia (NYT, 1996). A expectativa de vida das pessoas com SD é em média 56 anos em países desenvolvidos e no Brasil gira em torno de 50 anos, sendo maior com avanços na qualidade de vida e atendimentos especializados (Trindade e Nascimento, 2016).

Portadores de SD possuem características físicas como braquicefalia, pregas epicânticas, base do nariz chata, língua hipotônica, quando crianças possuem deficiência intelectual variada (Dessen e Silva, 2002). Devido à lesão no sistema nervoso central e funcionamento peculiar no envio de sinapses elétricas, o desenvolvimento cognitivo é afetado, principalmente, nos reconhecimentos estruturais e na linguagem (Luria e Tsvetkova, 1964). Além do atraso no desenvolvimento da linguagem, esse quadro podese tornar complexo pela "instabilidade na produção vocal, organização gramatical pobre e fala funcional quando adquirida" (Tristão e Feitosa, 1998, p. 135). 
IX Congresso Brasileiro de Informática na Educação (CBIE 2020)

Anais do XXXI Simpósio Brasileiro de Informática na Educação (SBIE 2020)

\subsection{Desenvolvimento da Linguagem em Crianças com Síndrome de Down}

A linguagem é a capacidade de comunicação considerada a primeira forma de socialização de uma criança, realizada pelos pais por instruções verbais em atividades cotidianas e histórias. Essa socialização pode ocorrer implicitamente, tendo interações verbais com leves marcações de status e papéis (Ely e Gleason, 1996). O Quadro 1 mostra as fases do desenvolvimento da linguagem, comparando crianças com e sem SD.

Quadro 1. Desenvolvimento da Linguagem em Crianças sem e com SD

\begin{tabular}{|c|c|c|}
\hline \multicolumn{3}{|c|}{ Comunicação Pré-Linguística } \\
\hline & Sem SD & Com SD \\
\hline Contato Visual & Aparece na $4^{\mathrm{a}}$ semana após o nascimento & Aparece somente na $6^{a}$ ou $7^{a}$ semana \\
\hline Balbucio & Surge aos 7 meses & Surge aos 9 meses \\
\hline \multicolumn{3}{|c|}{ Primeiras Palavras } \\
\hline Vocabulário (2 anos) & 250 palavras & 24 palavras \\
\hline \multicolumn{3}{|c|}{ Primeiras Sentenças } \\
\hline Duas palavras & Apenas 50 palavras & Necessitam $\cong 100$ palavras \\
\hline Três palavras & $\begin{array}{l}\text { Possuem compreensão de regras para } \\
\text { unir palavras }\end{array}$ & $\begin{array}{l}\text { Dificuldade na compreensão de } \\
\text { regras e formar sentenças }\end{array}$ \\
\hline
\end{tabular}

Por meio da linguagem, a criança obtém acesso a crenças, regras e valores, adquirindo conhecimento da sua cultura, antes de aprender a falar. À medida que se desenvolve, alcança nível cognitivo e linguístico elevado, tendo o campo da socialização expandido, quando a criança vai para escola e passa a ter oportunidade de interagir com outras crianças (Borges e Salomao, 2003).

\subsection{Aprendizagem}

Segundo Hamze (2014), aprendizagem tem objetivos classificados nos domínios: Cognitivo, Afetivo e Psicomotor. Cognitivo são capacidades intelectuais: habilidades de memorização, síntese, avaliação, compreensão e análise. Afetivo são os sentimentos, atitudes e gostos, representados por habilidades de receptividade, caracterização e resposta. Por fim, o domínio Psicomotor ressalta a coordenação dos músculos, demonstrado por atividades de movimentos básicos e reflexos.

O processo de aprendizagem é baseado em experiências, divididas em níveis crescentes de complexidade (Fernandez, 1991): sensação, percepção, formação de imagem, simbolização e conceituação. Hierarquicamente, tais níveis estão relacionados entre si, sendo que a relação inicia nos neurônios naturais, pelo processo de impulsos de entrada, que são captados e interpretados. Conforme o resultado é gerado um impulso de saída no formato de resposta, neste caso a aprendizagem.

No que tange às dificuldades de aprendizagem, como as causas são variadas, um acompanhamento profissional se faz necessário para identificada da causa dessa condição. Do ponto de vista educacional, essas dificuldades são formas de impedimento que pode afetar a fala, escrita e leitura, criando uma grande diferença entre a realização escolar e o potencial do aluno. Alguns sintomas podem ser observados por profissionais especializados e professores já na fase pré-escolar, sendo alguns deles problemas de linguagem, problemas de memória e déficit de atenção. Assim, não é um único fator, mas a combinação de diversos, que interferem diretamente na aprendizagem da criança.

\subsection{Jogos Digitais}

Os jogos digitais usam recursos tecnológicos para execução, desenvolvem interação entre um jogador humano e outro jogador, humano ou não, mediada por dispositivo de 
IX Congresso Brasileiro de Informática na Educação (CBIE 2020)

Anais do XXXI Simpósio Brasileiro de Informática na Educação (SBIE 2020)

processamento digital, denominado computador (PIACE, 2011). Computadores, videogames, celulares e smartphones são exemplos de dispositivos, que permitem execução de jogos digitais.

Segundo Battaiola (2000), o jogo digital possui três partes. O enredo define a história do jogo, objetivos e acontecimentos. O motor é o mecanismo que controla a reação, conforme a ação e decisão do jogador. A interface é onde se dá a interação entre o jogador e o motor, fornecendo a entrada e saída de comandos e respostas audiovisuais.

Os jogos digitais auxiliam na formação de agrupamentos, que têm conexões parecidas com as observadas na prática de elaboração de conceitos (Vigotski, 2008). Para Mattar (2010), o jogo desenvolve no jogador a aprendizagem involuntária, na qual não há a percepção do aprendizado e fazem com que ele tente desvendar os próximos estágios do jogo. A intenção ao se desenvolver um jogo é estimular a capacidade intelectual para superar desafios propostos, podendo ganhar ou não recompensa ao final.

Portnow e Floyd (2019) descrevem outra forma de aprendizagem, a tangencial, baseada em informações com maior grau de relevância e melhor assimiladas e, ainda, o interesse por certos conteúdos despertados pelo jogo, mesmo que a aprendizagem não aconteça dentro do jogo. Assim, percebe-se que o uso de elementos presentes nos jogos, como pensamentos, estratégias e mecânicas podem promover aprendizagem e ajudar na solução de problemas, fazendo o aprender ser mais significativo para o aluno.

Usar jogos educativos para o aprendizado de crianças é eficaz, pois já possuem contato com eletrônicos (tablets e smartphones) desde pequenas e estudos comprovam que habilidades de raciocínio e coordenação são beneficiadas com os jogos. Para Piaget (2000), criança que joga desenvolve a experimentação, sociabilidade e percepção. Embora, o autor não se refira aos jogos digitais, isso pode ser adaptado a esse contexto.

Outros estudos mostram que quem joga videogame apresenta um significativo aumento nas habilidades motoras, se comparados as pessoas que não jogam (Griffith et al., 1983). Os jogos cognitivos podem contribuir no processo de aprendizagem em uma perspectiva integral da pessoa. Para Lee e Jones (2008), a educação ajuda no desenvolvimento do cérebro, envolvendo a aprendizagem de exercícios e práticas que transformam e melhoram o funcionamento do cérebro.

Como as atividades são interativas e simples, jogos digitais tornam o aprendizado atrativo, despertando vontade de aprender em crianças. Embora, existam jogos similares ao proposto já disponíveis no mercado, em análise comparativa, tais jogos não são voltados exclusivamente para crianças especiais. Além disso, estudos anteriores proporcionaram aprendizado de forma lúdica e divertida às crianças envolvidas (Detânico e Konrath, 2019; Thome e Colling, 2018; Carneiro e Costa 2017). Tais trabalhos evidenciaram que o uso de jogos digitais no aprendizado de crianças especiais foi de grande valia, mas eram voltados para desenvolvimento de habilidades motoras e não da fala. Esse é o foco e situação problemática do presente trabalho, diferenciando-o desses demais estudos.

\section{Método de Pesquisa}

Essa pesquisa caracteriza-se pelo enfoque qualitativo e natureza aplicada. O método de pesquisa predominante adotado para projetar, desenvolver e avaliar o protótipo foi Design Science Research (DSR) (Dresch, Lacerda e Antunes, 2015), com o primeiro ciclo de avaliação feito por um estudo de caso, num contexto real. $\mathrm{Na}$ análise e modelagem do protótipo criado realizou-se revisão da literatura e de produtos similares 
IX Congresso Brasileiro de Informática na Educação (CBIE 2020)

Anais do XXXI Simpósio Brasileiro de Informática na Educação (SBIE 2020)

no mercado e entrevistas com especialistas, a fim de obter embasamento teórico e requisitos, voltados para a educação de crianças especiais.

A unidade de análise do primeiro ciclo de avaliação desse estudo foi uma escola de educação especial de Curitiba/PR, fundada em 1981, que possui 40 colaboradores e 56 alunos. Os sujeitos envolvidos nessa pesquisa foram 19 crianças especiais, na faixa etária de 3 a 5 anos, que apresentam dificuldades na aprendizagem da linguagem.

Em 29 de julho de 2019 foi aplicado um questionário impresso (Aaker et al., 2001), junto à fonoaudióloga dessa instituição, para fins de levantamento de requisitos e principais dificuldades das crianças no desenvolvimento da linguagem, visando obter dados e a definição de qual o melhor tipo de jogo. As perguntas foram baseadas na comparação do desenvolvimento da linguagem oral de uma criança neurotípica, na idade de 3 a 5 anos, com crianças que possuem SD, nessa mesma faixa etária. Também foi questionado à especialista sobre a situação do uso de recursos digitais na escola, com as crianças envolvidas e quais os tipos de atividades eram atrativos, na sua percepção. Nesse mesmo dia, um dos pesquisadores fez visita guiada, em observação direta das crianças, métodos de ensino e instalações da escola. Ainda, na coleta de dados se fez pesquisa documental em dados secundários (Gil, 2009), em documentos e site oficial da escola, visando conhecer a sua história e atividades desenvolvidas com as crianças.

Após o período de adaptação com a primeira versão do jogo, um pesquisador fez nova entrevista com a fonoaudióloga sobre a facilidade de uso do jogo, identificação de problemas e melhorias e sugestões para novas atividades. Essas entrevistas se repetiram a cada entrega de um novo jogo, até o alcance consensual dos objetivos do protótipo.

Os dados obtidos foram analisados quanto aos temas relacionados à linguagem, por meio da técnica de análise de conteúdo para então se iniciar a etapa de criação do protótipo em si. A partir dessa análise foram desenvolvidos protótipos de jogos para serem usados em tablets e smartphones em Android, conforme próxima seção. Depois, no final do período de utilização do protótipo, se analisou os registros de entrevista dos responsáveis da instituição, para saber como foi o desenvolvimento das crianças e a recepção por parte dos usuários. Esses feedbacks foram analisados e a partir deles, os protótipos foram aprimorados, conforme resultados da seção 4 desse artigo.

Em resumo, a pesquisa seguiu etapas do método DSR (Dresch, Lacerda e Antunes, 2015): (i) Conscientização: revisão de literatura, identificação do problema, definição do escopo; (ii) Sugestão: aplicação do questionário junto à fonoaudióloga da escola do estudo de caso, observação direta no local, elicitação de requisitos e sugestão dos protótipos dos jogos; (iii) Desenvolvimento: aprendizado sobre o framework e ambiente de desenvolvimento dos jogos, análise, projeto e desenvolvimento dos protótipos em si; (iv) Avaliação: execução do primeiro ciclo de avaliação dos protótipos pelos usuários do estudo de caso por 4 meses e análise de feedbacks dos profissionais. Nessa etapa, houve suspensão do segundo ciclo de avaliação sob DSR, pelo isolamento social imposto pela pandemia de Covid-19; (v) Conclusão: aprimoramento da versão inicial dos protótipos, com base nesse primeiro ciclo de avaliação, análise de resultados e conclusão. Destaca-se que visando promover conhecimento e melhorias evolutivas ao artefato, futuros ciclos de avaliação (iv) ainda estão previstos, após a pandemia.

\section{Resultados}

Nessa seção se apresenta o protótipo em si e uma análise de uso do jogo pelas crianças, no primeiro ciclo de avaliação. Durante esse ciclo, o acompanhamento dos pesquisadores foi por meio de feedbacks passados constantemente pela fonoaudióloga, 
IX Congresso Brasileiro de Informática na Educação (CBIE 2020)

Anais do XXXI Simpósio Brasileiro de Informática na Educação (SBIE 2020)

contendo informações de desempenho dos protótipos, quanto à utilidade e efetividade: (i) situação do uso dos jogos; (ii) dificuldades das crianças e profissional; (iii) sugestões de melhorias nas atividades; (iv) evolução das crianças acerca da fala e outros aspectos.

\subsection{Requisitos de Funcionamento e Arquitetura do Software}

Entre os requisitos não funcionais foi adotado o HTML 5, que possui a funcionalidade de tag Canvas, que permite composições de fotos e animações, através de Application Programming Interface (API) ou Javascript (MDN, 2019b). Essa tag Canvas é a base do desenvolvimento dos jogos, no Construct 2. O Construct 2 é um framework capaz de desenvolver jogos em HTML 5, podendo executá-los em diversos dispositivos (tablets, smartphones) e navegadores. Devido às suas características é eficiente na produção de jogos multi-plataformas (CONSTRUCT 2, 2019).

Usa GitHub, uma plataforma web que possui funcionalidades aplicadas ao git e gerencia versões de projetos, além de permitir que o usuário trabalhe em projetos colaborativos, planeje seus projetos e acompanhe o trabalho (BRENDON, 2019). No que tange à base de dados, o protótipo não possui por visar estímulo, não requerendo armazenamento de dados. Quanto aos requisitos funcionais, em resumo os jogos possuem funcionalidades de arrasto de imagens, emissão de sons em dadas ações, além da própria função touch, que permite que o jogo seja utilizado em smartphones.

\subsection{O Protótipo do Jogo Brincando com os Sons (BcS)}

Após levantamento de dificuldades observadas no desenvolvimento da fala em crianças com SD, junto aos usuários e fonoaudióloga da escola, recursos digitais foram buscados para auxiliar na estimulação da fala, aprendizado de maneira lúdica e desenvolvimento de habilidades cognitivas. Então, a versão Beta de um jogo móvel foi desenvolvida, com atividades de estímulo à fala de crianças especiais, na faixa etária dos 3 aos 5 anos, conforme Figura 1. Para tanto, o BcS apresenta vozes e sons, toda vez que o objetivo é atendido, permitindo à criança a repetição e audição da pronúncia.

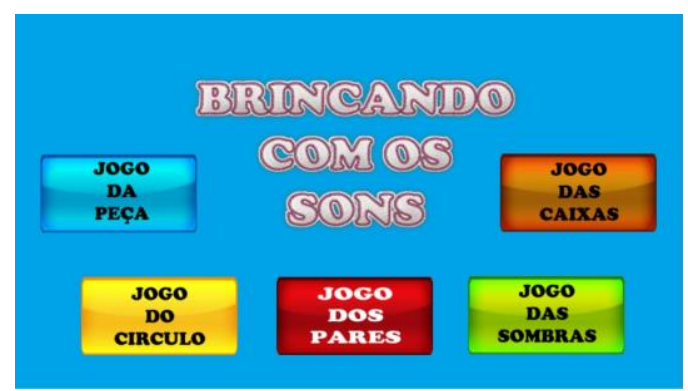

Figura 1 - Menu Principal do BcS

Esses jogos são de baixo grau de complexidade, visando o estímulo a acertos e erros. Com base na literatura revisada, requisitos e informações da especialista, os jogos da Figura 2 foram projetados com 3 níveis cada: Jogo da Peça (a), Jogo do Círculo (b), Jogo dos Pares (c), Jogo das Sombras (d) e o Jogo das Caixas (e).



Figura 2 - Telas principais dos jogos constituintes do BcS 
IX Congresso Brasileiro de Informática na Educação (CBIE 2020)

Anais do XXXI Simpósio Brasileiro de Informática na Educação (SBIE 2020)

Em resumo, o jogo (a) visa fazer com que a criança encontre a peça faltante e arraste até ao local correto. Ao encontrar a peça correta é emitido o som do nome da figura para que a criança identifique a pronúncia e possa repetir. $\mathrm{O}$ jogo (b) visa fazer com que a criança encontre entre as figuras a que lhe é solicitada. Ao tocar nas corretas surge um círculo ao redor, indicando acerto. Ao acertar, é emitido o som onomatopaico da gravura, isto é, o som que o animal real emite e que as pessoas tentam reproduzir.

$\mathrm{O}$ jogo (c) visa fazer com que a criança encontre figuras correspondentes. Ao tocar na figura desejada, aparece um símbolo usado para auxiliar na identificação visual de quais figuras são seus pares. Ao encontrar o par ou ao tocar no nome das figuras na parte inferior da tela é emitido o som com a pronúncia do nome da imagem. O jogo (d) visa fazer com que a criança encontre a sombra correspondente, arrastando a figura até ela. Ao acertar, é emitido o som onomatopaico da gravura ou sua pronúncia, sendo possível escutar novamente ao tocar na figura, após estar posicionada de forma correta a sua sombra. O jogo (e) visa fazer com que a criança "guarde" o objeto dentro de caixas. Ao arrastar o objeto à caixa, o som com a pronúncia do nome da figura é emitido.

\subsection{A Utilização do Jogo Digital em Ambiente Real}

O protótipo do BcS foi usado durante 4 meses, sendo avaliado em contexto real de uso, visando aferir seu desempenho quanto à utilidade e efetividade para estimular o desenvolvimento de habilidades, sobretudo no que se diz respeito à fala de crianças especiais matriculadas nessa escola objeto de análise.

A primeira experiência de uso foi iniciada em agosto de 2019 e concluída no final do mesmo mês, com apenas duas atividades para que aluno e a fonoaudióloga pudessem realizar uma adaptação. Os dispositivos utilizados foram um celular Samsung A3, da própria profissional, com a versão do Android 4.4 e um Samsung S7, com versão do Android 8.0. Nesse período, segundo a profissional, as 19 crianças envolvidas na pesquisa, com 3 e 4 anos de idade, ao acertarem demonstravam surpresa ao escutar o som, mostravam expressões faciais de felicidade e vibravam realizando gestos com os braços. Observou-se que as crianças com 5 anos de idade ao acertarem e escutarem o som emitido tentavam repeti-lo, na sequência.

Entre setembro e outubro de 2019, novas atividades e os jogos da primeira versão do protótipo foram aprimorados. Durante avaliação dessa nova versão, a especialista relatou que algumas das mesmas crianças, com 3 e 4 anos, que usaram a primeira versão tentavam emitir o som produzido pela gravura, na sequência ao uso. Já, as crianças com 5 anos, continuavam a repetir os sons.

No final de outubro e em novembro de 2019, novos níveis de complexidade em cada um dos jogos foram feitos e nova versão foi liberada para fins de avaliação. A especialista relatou que as crianças envolvidas já estavam adaptadas aos jogos. Crianças com 3 e 4 anos continuaram a emitir alguns sons onomatopaicos. Já, crianças com 5 anos continuaram a pronunciar as palavras, conforme eram emitidas pelo jogo, embora, com algumas trocas fonêmicas como "macaco" por "madado", "cachorro" por "cacholo" ou omissão da sílaba, "sapato" por "pato".

Ao final desse primeiro ciclo de avaliação da etapa "Avaliação" de DSR, realizada com as 19 crianças envolvidas da escola observou-se que as crianças de 3 e 4 anos necessitaram de auxílio para realizar as atividades propostas nos jogos, enquanto, as crianças com 5 anos realizaram as atividades sozinhas, de modo independente. Os jogos mais atraentes foram o Jogo das Sombras (d) e o Jogo das Caixas (e). O Jogo dos Pares (c) apresentou maior dificuldade cognitiva, pela não identificação de elementos 
IX Congresso Brasileiro de Informática na Educação (CBIE 2020)

Anais do XXXI Simpósio Brasileiro de Informática na Educação (SBIE 2020)

iguais, pois as crianças apertavam figuras aleatoriamente, aguardando a pronúncia do som para que pudessem repetir.

Para o profissional especializado em educação especial, o uso do jogo digital foi válido como ferramenta de apoio ao desenvolvimento da fala e cumpriu de modo satisfatório o intuito de entreter e aprimorar o coeficiente de aprendizado das crianças especiais envolvidas na pesquisa. Permitiu o uso de diversos fonemas e figuras de modo concentrado em um jogo, podendo ser utilizado em dispositivos móveis, como o celular. Sob o método DSR, os achados do primeiro ciclo permitem inferir que o desempenho do protótipo do $\mathrm{BcS}$ foi positivo de modo geral, atendendo ao propósito de desenvolver a linguagem de crianças especiais com SD, na faixa etária de 3 a 5 anos. Como pode ser observado, essa evolução das crianças foi evidenciada durante o uso, no estudo de caso.

\section{Discussão}

$\mathrm{O}$ avanço da tecnologia permitiu a inclusão de pessoas com necessidades especiais, em ambientes educacionais. Visando adaptações para atender a esse público, as escolas estão buscando novos recursos, que possam ser utilizados no ensino e aprendizagem de alunos especiais. Diante do cenário observado nessa pesquisa, se percebeu que o uso de recursos digitais na metodologia de ensino e na estimulação é pequena por parte dos profissionais, talvez pelo desconhecimento da existência de ferramentas. Uma criança com SD pode ter sua capacidade de aprendizagem limitada, por não ser oferecido a ela recursos adequados para o seu desenvolvimento. Esses recursos podem proporcionar maior potencialização de aprendizado dessas crianças.

Reconhece-se que a inclusão digital nas escolas pode ser um desafio, pelas melhorias e investimentos necessários na infraestrutura tecnológica, entre outros recursos, inclusive, os humanos especializados para que a inclusão aconteça de fato. Segundo Lima (2007), as tecnologias digitais precisam estar alinhadas aos processos educacionais e na educação especial, isso não é diferente.

Em relação aos estudos anteriores, $\mathrm{BcS}$ se mostrou diferente pelas características de portabilidade e de praticidade pela possibilidade de execução em dispositivos móveis, permitindo aprendizado quando necessário e em quaisquer locais. Quanto às limitações, atualmente pode ser usado apenas em Android, dificultando a adoção em contextos de uso e entre profissionais, que possuem iOS. Outro ponto é o uso individual, ou seja, uma criança por vez, ao contrário do que observou Carneiro e Costa (2017).

Conforme seção 2, um jogo digital é composto pela interação entre o jogador e o jogo. As crianças que usaram o protótipo interagiram de forma efetiva, pois todas as atividades propostas dependiam de uma ação, seja ela arrastar ou tocar, para houvesse uma reação audiovisual e assim, demonstraram que o objetivo da tarefa foi atendido. Por sua vez, comprovaram que crianças especiais levam um tempo maior na aquisição da fala e que o jogo $\mathrm{BcS}$ pode auxiliar nesse desenvolvimento.

$\mathrm{O} \mathrm{BcS}$ mostrou-se útil e eficaz no contexto avaliado, permitindo ao profissional especializado aprimorar estimulação da fala das crianças envolvidas, bem como mantêlas entretidas durante o aprendizado. Tal recurso se mostrou vantajoso para fins de aprendizagem, porque concentra no jogo diversas figuras e fonemas, além de fácil utilização e linguagem voltada ao público alvo. Ademais, levar recursos digitais às crianças especiais ainda é um desafio, no cenário nacional. Promover essa inclusão é desafiador na área da educação, porém, não impossível, quando existe vontade e interesse de voluntários ou não. Esse estudo é um exemplo prático e demonstra que a educação é um direito de todos, possuindo a criança certas limitações ou não. 
IX Congresso Brasileiro de Informática na Educação (CBIE 2020)

Anais do XXXI Simpósio Brasileiro de Informática na Educação (SBIE 2020)

\section{Considerações Finais}

A educação é um processo que prepara indivíduos para enfrentar situações que a vida lhes impõe. Tecnologia é um conhecimento teórico aplicável na prática, pressupondo saber científico. O uso de jogos digitais como recurso tecnológico na educação especial serviu na pesquisa como ferramenta para planejar, implementar, incrementar e avaliar o processo de desenvolvimento da fala, em crianças portadoras de necessidades especiais.

Torna-se oportuno salientar que se deve estender o uso de recursos digitais para além de suportes materiais. Tecnologia no apoio à aprendizagem é mais do que uso de ferramentas, objetos e conhecimentos específicos, pois envolve postura afetiva, social, simbólica e conceitual pelo profissional envolvido no processo, como acompanhado pelos pesquisadores nesse estudo de caso. Nesse estudo foi desenvolvida uma versão Beta de jogos educativos cujos objetivos foram de encontro às dificuldades no desenvolvimento da fala de crianças portadoras de necessidades especiais, com SD visando a interatividade destas crianças com a ferramenta. $O$ uso de recursos tecnológicos pelo profissional de fonoaudiologia, junto às crianças envolvidas na pesquisa mostrou ser um dispositivo valioso no processo de aprendizado, durante o período de uso na escola, nesse primeiro ciclo de avaliação de DSR.

Com isso, se percebe que há espaço no mercado de jogos digitais para exploração de conteúdos voltados para a educação especial e de jogos em que crianças possam desenvolver habilidades cognitivas de forma lúdica e atraente. Considera-se que o presente estudo contribuiu significativamente nesse sentido, ao projetar, desenvolver e avaliar um artefato útil para essa classe de problemas da educação especial e mercado de jogos digitais, podendo ser disponibilizado para domínio público, após novos testes.

No âmbito de jogos educacionais, essa pesquisa mostrou que o uso da tecnologia pode ser um aliado à educação, potencializando atividades e o aprendizado. Apresenta achados que contribuem para o desenvolvimento de jogos sérios digitais para apoiar o processo de aprendizagem, voltados para necessidades especiais de crianças, que pode ser expandido e explorado futuramente por profissionais e pesquisadores dessa área. É um exemplo de aplicação método DSR para criação de artefatos relevantes e úteis para solução de um problema real de educação especial. Proporciona evidências de impacto desses artefatos, observado e medido em contexto real de uso.

Como trabalhos futuros sugere-se a possibilidade da aplicação deste elemento educativo em diferentes ambientes reais relacionados ao ensino, de maneira a funcionar como estímulo ao educando e ao profissional envolvido, proporcionando a implantação e o emprego de novas rotinas e estratégias de ensino, bem como realizar a portabilidade para o sistema operacional $i O S$, visando ampliar sua adoção e quantidade de usuários.

\section{Referências}

Aaker, D. A. et al. (2001) “Marketing Research”, John Wiley Sons, Inc.

Battaiola, A. L. (2000) "Jogos por computador: Histórico, relevância tecnológica e mercadológica, tendências e técnicas de implementação”. In Anais XIX JAI, p. 83.

Borges, C. and Salomao, N. M. R. (2003) “Aquisição da Linguagem: Considerações da Perspectiva da Interação Social”, http://www.scielo.br/pdf/prc/v16n2/a13v16n2.pdf.

Brendon, M. (2019) "O Que é GitHub e Para Que é Usado?, https://www.hostinger.com.br/tutoriais/o-que-github/. 
IX Congresso Brasileiro de Informática na Educação (CBIE 2020)

Anais do XXXI Simpósio Brasileiro de Informática na Educação (SBIE 2020)

Brites, L. (2019) "Como Ajudar Alunos com Dificuldade de Aprendizagem", https://neurosaber.com.br/como-ajudar-alunos-com-dificuldade-de-aprendizagem/.

Carneiro, R. U. C. and Costa, M. C. B. (2017) "Tecnologia e Deficiência Intelectual: Práticas Pedagógicas para Inclusão Digital”, https://periodicos.fclar.unesp.br/rpge/article/download/10449/6805.

Construct 2. (2019) Framework Construct 2, https://www.scirra.com/construct2

Dessen, M. A. and Silva, N. L. P. (2002) "Síndrome de Down: Etiologia, Caracterização e Impacto na Família”, https://revistas.ufpr.br/psicologia/article/download/3304/2648

Detânico, A. and Konrath, M. (2019) "O Uso de Jogos Digitais na Educação Infantil no CEI Casa da Criança Desenvolvidas”, https://bit.ly/3jiHdNI.

Dresch, A., Lacerda, D. P. and Antunes, J. A. V. J. (2015) "Design Science Research: Método de Pesquisa para Avanço da Ciência e Tecnologia”, Bookman.

Gil, A. C. (2009) "Como elaborar projetos de pesquisa", Atlas, 4. ed.

Griffith, J. L. et al. (1983) "Differences in Eye-Hand Motor Coordination of VideoGameUsers and Non-Users", Eastern Illinois University.

Hamze, A. (2014) "O que é a Aprendizagem", https://educador.brasilescola.uol.com.br/trabalho-docente/o-que-e-aprendizagem.htm

Lee, I. and Jones, J. (2008) "Full Bloom: A Brain Education Guide for Successful Aging”, SCB Distributors.

Lima, R. C. (2007) "O uso da tecnologia na educação especial", http://www.webartigos.com/artigos/o-uso-da-tecnologia-na-educacao-especial/1880/.

Lima, I. L. B., Delgado, I. C. and Cavalcante, M. C. B. (2016) "Desenvolvimento da Linguagem na Síndrome de Down: Análise da Literatura", https://revistas.pucsp.br/dic/article/view/28611/23007.

Luria, A. R. and Tsvetkova, L. S. (1964) "The Programming of Constructive Activity in Local Brain Injuries", Basic.

Mattar, J. (2010) “Games em educação: Como os Nativos Digitais Aprendem”, Pearson.

Nystrom, R. (2014) "Architecture, Performance and Games", https://gameprogrammingpatterns.com/architecture-performance-and-games.html.

Piace, M. T. (2011) "Jogo eletrônico, flow e cognição", https://tede2.pucsp.br/handle/handle/18075.

Prates, L. and Martins, V. (2013) "Distúrbios da Fala e da Linguagem na Infância", https://bit.ly/3n3FDBD.

Rangel, D. I. and Ribas, L. P. (2011) "Características da linguagem na SD: Implicações para Comunicação”, http://www.feevale.br/site/files/documentos/pdf/58652.pdf.

The New York Times, NYT (1994) "Dr. Jerome L. Dies at 67 Found Cause of Down Syndrome", https://nyti.ms/2GiNryG.

Thome, L. and Colling, J. (2018) "O Uso de Recursos Tecnológicos Digitais na Promoção da Aprendizagem de Pessoas com Deficiência”, https://bit.ly/3cJTjgn.

Tristao, R. M. and Feitosa, M. A. G. (1998) "Linguagem na Síndrome de Down”, http://periodicos.unb.br/index.php/revistaptp/article/download/17318/15819/. 